\title{
Examinar, enquadrar, adaptar o currículo e desenvolver a língua de sinais: estratégias de normalização de alunos surdos down em uma escola de surdos
}

Liège Gemelli Kuchenbecker*
Adriana da Silva Thoma**

\section{Resumo}

Partindo do entendimento de que a educação escolar moderna é sempre normalizadora, este trabalho problematiza as estratégias de normalização de sujeitos surdos down em uma escola de surdos. A pesquisa foi realizada por meio da análise de relatórios de avaliação e pareceres clínicos e de entrevistas com professoras que trabalham com os referidos alunos. Como ferramentas analíticas, utilizamos as noções de norma e normalização a partir do pensamento de Michel Foucault. As recorrências encontradas nos materiais possibilitaram a constituição das seguintes unidades de análise: (1) Pareceres clínicos: exame e enquadramento dos sujeitos, (2) Adaptação curricular como estratégia de normalização e (3) Normalização linguística: gerenciamento do risco da não-aprendizagem. Tais recorrências nos permitem supor que, na escola de surdos, ocorrem processos de in/exclusão similares a outros vividos em escolas comuns quando dela passam a fazer parte sujeitos que desviam de uma norma estabelecida.

Palavras-chave: Surdo; Síndrome de Down; Norma; Normalização; Inclusão.

\section{Examining, framing, adapting the curriculum and developing sign language: strategies to normalize deaf students with Down syndrome in a deaf school}

\begin{abstract}
From the understanding that modern school education is always normalizing, this paper problematizes strategies meant to normalize deaf subjects with Down syndrome in a deaf school. The research was carried out through the analysis of both evaluation and clinical reports, and interviews with teachers that work with those students. As analytical tools, we used the notions of norm and normalization, from Michel Foucault's theorizations. The recurrences found in the materials allowed for the constitution of the following analysis units: (1) Clinical reports:
\end{abstract}

\footnotetext{
* Mestre em Educação pelo Programa de Pós-Graduação em Educação (PPGEDU) da Universidade Federal do Rio Grande do Sul (UFRGS). Professora de surdos e intérprete de Libras. Porto Alegre, Rio Grande do Sul, Brasil.

** Doutora em Educação. Professora do Departamento de Estudos Especializados da Faculdade de Educação (DEE/FACED) e do Programa de Pós Graduação em Educação (PPGEDU) da Universidade Federal do Rio Grande do Sul (UFRGS). Porto Alegre, Rio Grande do Sul, Brasil.
} 
examination and framing of subjects, (2) Curriculum adaptation as a normalization strategy, and (3) Linguistic normalization: management of non-learning risk. Such recurrences enabled us to assume that in/exclusion processes similar to those seen in regular schools also occur in the deaf school when subjects deviating from the established norm become part of it.

Keywords: Deaf; Down Syndrome; Norm; Normalization; Inclusion.

\section{Introdução}

Partindo do entendimento de que a educação escolar moderna é sempre normalizadora, o presente trabalho problematiza as estratégias de normalização de alunos surdos down em uma escola de surdos, no município de Porto Alegre/RS, quando nela ocorre a inclusão de alunos surdos down, sujeitos que se diferenciam dos demais surdos por apresentarem característica físicas/biológicas e outros tempos de aprendizagem.

A escola investigada é uma instituição que atende alunos surdos desde os anos de 1950. No início, a proposta educacional era oralista (ensinava os surdos a falar e fazer leitura labial), mas, com o decorrer dos anos, a educação passou a desenvolver uma proposta utilizando o método da Comunicação Total (uso simultâneo de fala, sinais e outros recursos associados para a comunicação com os surdos). Na década de 1990, a escola assume a proposta da educação bilíngue, na qual a língua de sinais é reconhecida como primeira língua e língua de instrução, sendo a língua portuguesa escrita considerada como segunda língua para os surdos.

A pesquisa foi desenvolvida em uma época e em um contexto em que os debates sobre a inclusão escolar estão muito presentes, tanto nas escolas comuns como nas escolas de surdos. A escola onde a pesquisa foi realizada vem passando por reformulações desde a sua constituição e, atualmente, as discussões sobre a inclusão de surdos com deficiências associadas se tornaram uma preocupação, pois essa era uma instituição escolar que antes atendia um perfil de surdos que aprendiam a língua de sinais rapidamente quando em contato com outros surdos. Acreditava-se que a aprendizagem e o uso dessa língua por parte dos alunos e professores viabilizava as condições de ensino, embora o processo educacional ficasse reduzido às questões linguísticas. Quando alunos com deficiência associadas à surdez, com outros perfis e ritmos de aprendizagem, entram na escola, os professores se deparam com novos desafios e se sentem despreparados para atendê-los.

Tomamos como material de análise documentos de avaliação clínica e pedagógica produzidos entre os anos de 2006 e 2010 e enunciados dos professores sobre os alunos surdos down, alunos que estavam anteriormente em clínicas, em escolas especiais ou escolas comuns com intérprete de Língua de Sinais e agora estão incluídos na escola de surdos. 
As noções de norma e normalização desenvolvidas por Michel Foucault são nossas ferramentas de análise e problematizações feitas por autores que trabalham na esteira de seu pensamento, tais como, François Ewald (1993), Márcio Alves da Fonseca (1995) e Vera Portocarrero (2004) também nos auxiliam a olhar para os materiais.

Sobre o conceito de normalização, Fonseca (1995, p. 58) escreve:

A normalização não é resultado de uma forma de repressão, mas técnicas de sanções voltadas para uma operacionalidade. Ela envolve uma classificação e a qualificação de atos e comportamentos sutis, obriga à escolha de valores, permitindo a diferenciação dos indivíduos e a mensuração de sua natureza e capacidade [...] tende a uma homogeneidade conseguida a partir de uma atuação sancionada no nível individual em que desvios e inobservâncias ocorrem.

A normalização visa a aproximação e a minimização das diferenças entre os sujeitos; tem como propósito a homogeneização dos mesmos. Por isso, normalização é uma noção que se insere nas questões educacionais e operar com ela nos permite problematizar as diversas situações que ocorrem no campo educacional e que se entrecruzam com outros campos de saberes. A normalização que se insere no contexto escolar incide sobre os modos de ser e aprender dos sujeitos quando classifica, serializa, ordena e organiza os sujeitos escolares.

Em Segurança Território e População, Foucault (2009, p. 83) escreve que "a norma está em jogo no interior das normalidades diferenciais". É neste jogo que se operacionaliza a normalização, dentro da distribuição das normalidades, umas mais favoráveis que outras, mais normais que as outras.

Compilando os dados a partir dos documentos analisados e do uso das ferramentas norma e normalização, chegamos ao que podemos denominar de estratégias de normalização dos sujeitos surdos down. A seguir, apresentamos as unidades de análises em que podemos ver as estratégias para normalizar os surdos down desenvolvidas na escola, unidades que foram constituídas com o uso das lentes teóricas que utilizamos para olhar para os dados que nos foram disponibilizados.

\section{Pareceres clínicos: exame e enquadramento dos sujeitos}

Os saberes das áreas médicas constituem as possibilidades de se dizer determinadas coisas sobre os sujeitos surdos down através de documentos e pareceres (descritivos/prescritivos). Pela ordem do discurso e legitimidade social que possuem, esses saberes, quase sempre, acabam sendo aceitos como verdades pelos pais e demais profissionais envolvidos no trabalho com os 
alunos surdos down, sendo raramente questionados, postos sob suspeita ou problematizados.

A avaliação clínica é feita por diferentes profissionais da área da saúde (assistente social, psicóloga, fonoaudióloga e médico otorrinolaringologista, sendo esse último o profissional que confirma ou não a surdez do aluno candidato à escola) e a reunião de todos os pareceres se constitui em uma Hipótese Diagnóstica do sujeito, segundo a qual o aluno avaliado poderá ou não ingressar na escola de surdos, pois o objetivo da avaliação clínica conjunta é verificar se o sujeito se enquadra ou não no perfil de alunos atendidos pela escola de surdos. Nesse contexto de avaliação, entendemos os pareceres clínicos como exigências coletivas, produzidas pelos profissionais da saúde que se reúnem e elaboram um diagnóstico em conjunto, no qual prescrevem as exigências que devem ser seguidas pelos sujeitos e por suas famílias para que possam estar na escola.

A Hipótese Diagnóstica realizada em conjunto com os profissionais da clínica sobre a jovem surda down, Alice, descreve que a conduta da aluna:

[...] é agitada, dispersiva, com risos imotivados e dificuldade compreensiva. Mostra-se intolerante em alguns momentos, com dificuldades no controle dos impulsos, respondendo ao manejo firme e claro. Deverá dar continuidade aos atendimentos individuais. (2004)

À Hipótese Diagnóstica e aos sentidos que lhe são atribuídos, entendemos que ela se relaciona ao que Foucault (2005, p. 157) denominou de exame, o qual:

[...] coloca os indivíduos num campo de vigilância, situaos igualmente numa rede de anotações escritas; compromete-os em toda a quantidade de documentos que os captam e os fixam. Os procedimentos de exame são acompanhados imediatamente de um sistema de registro intenso e de acumulação documentária. Um 'poder de escrita' é constituído como uma peça essencial nas engrenagens da disciplina.

Os surdos down que fizeram parte da pesquisa são os filhos mais jovens de suas famílias. As suas mães engravidaram entre 37 e 40 anos de idade, estimativa feita a partir do Estudo Social das famílias, com base na idade dos pais no dia da primeira entrevista e idade dos jovens surdos down nessa mesma época. Apenas uma das jovens sugere ter ficado surda após o nascimento, em decorrência de meningite bacteriana aos oito anos de idade.

Os discursos regulares nos diagnósticos individuais e nas Hipóteses Diagnósticas conjuntas enunciam que os sujeitos surdos down "apresentam defasagem de aprendizagem", "comunicam-se por gestos próprios", "necessitam de maior estímulo". 
As Hipóteses Diagnósticas são finalizadas com um Prognóstico para os sujeitos ingressantes na instituição. No caso de Alice, não há Prognóstico, e sim Recomendações Profissionais que orientam a participação da aluna no Trabalho Educativo da escola, uma atividade que envolve a reciclagem de papel e fonoterapia. Para o jovem surdo down, Cláudio, há um Plano Terapêutico, que indica um "maior estímulo na aprendizagem". O Prognóstico para a terceira jovem surda downé "regular face as condição de Bárbara"e o de Claudio "regular diante [de] dificuldade e limitações apresentadas".

Assim, tanto os Prognósticos como os Planos Terapêuticos e outros documentos são revestidos de "um poder da escrita" (FOUCAULT, 2005) que visa ao disciplinamento do sujeito a partir de sua inserção na escola, através da sua participação e envolvimento nos atendimentos individuais. A Hipótese Diagnóstica, assim como o Prognóstico, mostra um poder-saber dos profissionais da área médica quando estes prescrevem os encaminhamentos a serem seguidos pelas famílias dos jovens surdos down quando esses ingressam na escola.

A psicóloga da escola, como resultado de sua avaliação dos surdos down, elaborou os seguintes pareceres:

Alice demonstrou comportamento dispersivo com dificuldade para conter seus impulsos, necessitando a intervenção da mãe a todo o momento. Segundo a mãe, Alice é autoritária, porém carinhosa e responde ao manejo firme. Alice mostra-se intolerante, porém executa as solicitações com dificuldade. Apresenta conduta de desenvolvimento global e intelectual não compatível com a sua idade. (2004)

Durante a avaliação, Bárbara manteve-se atenta a tudo, participando sempre que solicitada. Até a presente data, não consegue escrever seu nome, indicando grande defasagem e dificuldades na aprendizagem. (2006)

Durante a avaliação, Cláudio demonstrou impaciência, busca de atenção constante, afetividade e desejo estudar. (2008)

No que se refere à avaliação do médico da escola, este descreve clinicamente os sujeitos, cujos registros detalhados desses possibilitam "[...] manter a singularidade que aparece em cada individualidade, com seus desvios, seus traços particulares, suas aptidões e capacidades"(FONSECA, 1995, p. 60). Segue abaixo um exemplo desses registros:

Jovem portador de perda auditiva neurossensorial profunda bilateral. Não está protetizado. Comunica-se com familiares por linguagem de sinais próprias e algumas palavras em LIBRAS [...] Portador de Síndrome de Down. Frequentemente agitado. (2008) 
As Hipóteses Diagnósticas, assim, prescrevem ações que objetivam a normalização do sujeito surdo down. Exemplo disso são as solicitações de exames audiológicos que comprovem a surdez e os níveis de audição dos alunos, solicitações que são recorrentes, cujos retornos são dados em pareceres como o que segue:

Os achados audiológicos sugerem perda auditiva neurossensorial severa à profunda. Os limiares auditivos são aproximados. Foram obtidos através da mudança de comportamento e procura da fonte sonora com os olhos.

Os surdos down, na maior parte das vezes "não oralizam e não usam próteses" ou "não se adaptaram a usar as próteses, comunicam-se com gestos ou sinais próprios, com algumas palavras" e "estão evoluindo conforme suas limitações, apresentam risos imotivados, desorganizados e realizam pouco contato visual." Com tais descrições, vemos que o processo de normalização desses sujeitos tem início na clínica da escola, através de exames que buscam subsídios para propor estratégias que possam aproximar todos os surdos da norma prevista nesse espaço, a qual vem sendo constituída pelos próprios discursos do movimento surdo, que para desconstruir a norma ouvinte como modelo para o surdo, acabou por criar outra norma, a de um surdo que possa ser fluente na língua de sinais e aprender através dela.

\section{Adaptação curricular como estratégia de normalização}

Com base na leitura dos objetivos previstos para as turmas em que estão os alunos surdos down, dos relatórios dos alunos e das falas das professoras, é possível perceber o quanto as adaptações curriculares, que vêm sendo elaboradas desde o ingresso da primeira aluna surda down em 2006, referem-se a padrões comportamentais a serem alcançados pelos alunos. De acordo com os materiais analisados, quando ingressaram na escola, os alunos surdos down demonstraram resistência ao novo ambiente escolar, porém, com o decorrer dos semestres ou trimestres letivos, foram atingindo ou atingindo parcialmente a maioria dos objetivos relacionados aos modos de ser e agir na escola e em sala de aula.

Os objetivos adaptados são fixados, a cada trimestre, pelos professores das turmas. Estes professores estabelecem, a partir das avaliações clínicas e do perfil de aprendizagem de cada um, o mínimo dos objetivos, pensados para toda a turma, a ser atingido pelos alunos surdos down. Conforme informações obtidas na Instituição, o currículo adaptado engloba objetivos e avaliações diferenciadas e transcorre paralelamente ao currículo regular, tendo como fundamentação e amparo legal o Parecer nํ02 do Conselho Nacional de Educação (CNE) que trata sobre o assunto. 
Os objetivos são construídos pelos professores, porém são analisados e avaliados pela supervisão da escola. Além dos objetivos, também os relatórios descritivos são lidos e avaliados pela supervisora, profissional que orienta os professores para a escrita dos mesmos. A escrita dos relatórios é uma técnica tanto de poder quanto de saber, construída a partir de uma vigilância das palavras.

Os objetivos adaptados aparecem nos documentos apenas quando os alunos passam a frequentar as turmas de surdos, e não mais a classe especial denominada "Turma de adaptação e aquisição da linguagem (TAAL)". O termo classe especial consta em um dos documentos da clínica em relação à aluna Bárbara:

neste ano entrou $\mathrm{p} /$ a 2' série junto com os demais colegas. Não está [mais] separada em classe especial. (Parecer clínico, 2009).

No excerto acima, "demais colegas" significa "surdos sem deficiência", que estão em turmas de ensino comum, nas quais a instrução acontece em língua de sinais. A classe especial, TAAL, iniciou, em 2006, com o ingresso da primeira surda down e outros surdos com deficiências, foi dissolvida no ano de 2008 e, em 2010, reapareceu a partir da configuração da turma de $2^{2}$ série do Ensino Fundamental de nove anos. Segundo a professora Natália:

São 5 alunos nesta turma [...] todo o grupo é com currículo adaptado, já em outras turmas, alguns [alunos] tem currículo adaptado e outros não. Todo esse grupo vai sair com uma certificação diferente, vai ser ou não integrado em outras turmas, isso a gente vai ver no final do ano, porque todo o final do ano é revisto. Não é mais TAAL, é uma turma que está dentro do currículo regular. O currículo não é um currículo de $2^{a}$ série, por exemplo. É um currículo que vai sendo construído durante o ano. (Professora Natália, 2010).

A explicação da professora nos provoca a pensar sobre as possíveis razões para a formação desse grupo, do qual fazem parte um aluno surdo down e outros quatro surdos com deficiências, descritos como "alunos com outros comprometimentos, com dificuldades". Será que estes alunos ficaram juntos por não se enquadrarem em nenhum outro grupo, ou, talvez, por se distanciarem, conforme os ditos das professoras, do "ser surdo puro ou surdo normal"? Algumas professoras falam sobre essa distribuição dos alunos nas turmas, como a exemplo da professora Patrícia, que entende que:

Se ela [Bárbara] estivesse num grupo especial que todos tivessem a síndrome de down não sei se ela teria alcançado tanta coisa como ela alcançou agora nesse ano. O grupo ajuda bastante. 
E a professora Mariana:

Por exemplo, se todos são surdos e mais down não tem como haver trocas, se todos são surdos e mais deficientes mentais profundos, não tem como haver trocas. Se há um surdo com deficiência mental em meio aos surdos normais, então sim, há possibilidades de trocas, pois são vários estimulando aquele um.

No final da entrevista, esta mesma professora se posiciona contrária à formação da turma da $2^{\mathrm{a}}$ série, em que se encontra o aluno Cláudio. Ela compara este grupo com as turmas em que estão inseridas as outras duas surdas down:

Por exemplo, na turma do Cláudio, todos têm problema e não tem troca. [...] a turma da $3^{\underline{a}}$ série, todos são bons e só há uma down, todos os colegas a estimulam, igualmente acontece com a $4^{\underline{a}}$ série, turma de Alice.

Os objetivos adaptados podem ser entendidos como estratégia de normalização, pois são traçados a partir de um padrão de aluno surdo normal, surdos sem deficiência. A finalidade desses objetivos é potencializar o aprendizado dos alunos surdos down, aproximando-os dos surdos sem deficiência, respeitando as limitações e capacidades individuais de cada sujeito. Esses termos são recorrentemente encontrados nos materiais analisados:

Alguns objetivos específicos foram listados para turma, porém, no caso de Cláudio, a sua socialização, internalização da rotina escolar e aquisição de sinais básicos foram os objetivos priorizados e alcançados por ele, dentro de suas potencialidades. (Relatório, 2008).

Conforme escrito acima, a turma se enquadra na referência de aprendizado de uma escola de surdos, e os dados nos permitem dizer que o aluno surdo desejado e que se insere nos padrões de ensino estabelecido pela Instituição é aquele capaz de ser fluente em língua de sinais, aquele que aprende através dessa a língua portuguesa e a matemática, aquele que seja capaz de compreender os conteúdos atentos às explicações e que, além desses aprendizados, possa se movimentar de forma rápida e ágil a partir dos exercícios psicomotores.

Os alunos surdos down não se encaixam nesse modelo ideal de ser aluno surdo, e o impeditivo parece estar na síndrome, conforme a avaliação de algumas professoras em entrevista: "isto é da Síndrome de Down e da deficiência mental que possuem" e nos comportamentos desviantes e estereotipados que também são descritos: "olha sempre para baixo"; "desvia o olhar quando estou explicando"; "não aceita o toque com facilidade"; "é muito afetivo e isso assusta às vezes os colegas"; "tem um toque muito forte"; "tudo tem que estar sempre muito organizado". 
A condução da conduta dos alunos surdos down, de seus modos de ser e de agir são produtivas, conforme consta em alguns relatórios de avaliação, pois esses alunos já conseguem se "socializar e internalizar a rotina escolar", mesmo que de forma repetitiva, ou seja, "copia os sinais da professora e colegas interagindo assim com o grupo".

A recompensa dos surdos down pela melhora de seus comportamentos e por se esforçarem em se aproximar ao ideal de aluno surdo,é ganhar atividades que se assemelhem às dos demais colegas surdos de sua classe, como: "ganhar a mesma folhinha", "o mesmo caderno", "copiarem do quadro" etc. Mas, do contrário, os surdos down permanecem nas mesmas atividades que são capazes de desempenhar: "pintar o desenho da história", "pintar com giz de cera ao invés do lápis de cor", como um sistema de sanção e gratificação analítica, em que a normalização pode se sustentar e se efetuar e que tem a ver com o que Foucault (1995) denominou de punição disciplinar. Em outras palavras, é a normalização dos detalhes que se firma na individualidade dos sujeitos.

As adaptações curriculares e os objetivos adaptados se configuram como uma das estratégias para normalizar os sujeitos surdos down, que, inseridos em um contexto escolar de surdos, precisam se adequar às regras da instituição. As adaptações curriculares se tornam estratégias de normalização quando buscam amenizar as diferenças dos alunos e quando se constituem como um meio de equilibrar a regra com a exceção, fazendo, assim, com que todos, em um mesmo espaço, não se igualem, mas se pareçam.

\section{Normalização linguística: gerenciamento do risco da não-aprendizagem}

Apresentamos, a seguir, excertos de objetivos, pareceres descritos, pareceres clínicos e falas de professoras que tratam sobre práticas relacionadas à normalização linguística, normalização que se busca através da língua de sinais. Tanto os documentos analisados, quanto os ditos das professoras que trabalham ou trabalharam com os surdos down, dizem sobre a necessidade e o modo desses alunos aprenderem sinais e de estarem interagindo com outros surdos.

Iniciamos com o excerto do primeiro relatório de avaliação da aluna Alice, elaborado no primeiro semestre de 2006, quando a aluna estava na turma especial (TAAL):

Participa com interesse das atividades propostas para a aula de LIBRAS, apresentando um rendimento significativo e desenvolvendo, gradativamente, a sua comunicação. Observa-se que a aluna compreende alguns sinais, embora apresente dificuldade em estabelecer relações entre o que sinaliza e o assunto trabalhado. 
Abaixo, outros dois excertos dos relatórios de avaliação emitidos em 2010, no $1^{\circ}$ e $2^{\circ}$ trimestres, respectivamente, com comentários sobre o desenvolvimento da aluna na disciplina da língua de sinais, quando ela estava matriculada na quarta série:

Está em processo de aquisição da Língua de Sinais e, portanto, apresenta ainda um vocabulário limitado.

Apresenta um bom desenvolvimento da linguagem compreensiva, mas ainda demonstea dificuldades para expressar-se com clareza na Língua de Sinais.

Os relatórios acima datam de anos diferentes, 2006 e 2010, porém abordam o aprendizado da língua de sinais de forma semelhante: Alice vem "desenvolvendo gradativamente a sua comunicação", "apresenta dificuldade em estabelecer relações", "dificuldade para expressar-se com clareza na língua de sinais", "apresenta ainda vocabulário limitado". Quatro anos separam o primeiro relatório dos demais, mas a avaliação parece ser a mesma, ou seja, mensurase a sinalização da aluna conforme as exigências de uma regra linguística utilizada por usuários fluentes em língua de sinais, professores ou colegas de classe.

Essas questões não se referem apenas à aluna Alice, mas a todos os alunos surdos down incluídos na escola de surdos. Os objetivos atingidos, nãoatingidos e atingidos parcialmente, bem como as regularidades presentes nos relatórios e ditos das professoras sobre a prática da língua de sinais na escola, fundamentam e gerenciam o risco da não-aprendizagem dos alunos surdos down.

Uma das finalidades da disciplina de língua de sinais para os alunos surdos down é gerenciar o risco da não-aprendizagem da primeira língua dos surdos (L1), a partir de propostas pedagógicas, tais como a "sinalização através de texto argumentativo"e "fixação de vocabulários através dos jogos pedagógicos", resultando na "ampliação do vocabulário na língua de sinais".

Risco é uma das "noções novas" que aparece junto com a noção de caso, perigo e crise, e é trabalhada por Michel Foucault em Segurança Território e População (2009). Noções novas por suas técnicas e aplicabilidade na população a partir do século XVIII. Para Ewald (1993), o risco é uma medida calculável e possibilita que sejam previstos os fenômenos que provocam riscos a determinada população.

No gerenciamento dos riscos sociais, os sujeitos surdos, entendidos pelas políticas educacionais como sujeitos com necessidades educativas especiais, "[...] podem ser entendidos como comunidade de risco, pois eles [...] em sua maioria, não são alfabetizados, vivem em condições de extrema pobreza, poucos têm acesso ao mercado de trabalho, o índice de escolarização é baixíssimo e a evasão escolar muito alta" (LUNARDI, 2003, p.154). Nesse sentido é que usamos uma das estratégias utilizadas para gerenciar a não-aprendizagem dos alunos surdos down. 
O gerenciamento do risco da não-aprendizagem visa possibilitar que os alunos surdos down possam finalizar o período letivo, através da minimização das diferenças que esses apresentam em relação aos demais surdos:

Dentro de suas possibilidades, alcançou a maioria dos objetivos propostos. Precisa ser estimulada [...] Considerando o desempenho da aluna [...] está aprovada para frequentar a $2^{\mathrm{a}}$ série do Ensino Fundamental dentro de uma proposta pedagógica adaptada as suas necessidades cognitivas. (Relatório, Alice, 2007)

Há uma busca por aproximar o aprendizado da língua de sinais dos surdos down com o aprendizado dos demais surdos, fazendo com que todos possam vir a se comunicar com os mesmos sinais de modo a compreender 0 que é ensinado pelos professores de forma semelhante. Busca-se, com isso, diminuir a distância entre as diferenças linguísticas dos alunos surdos downe dos demais surdos e professores que trabalham na escola.

Dos pareceres clínicos, extraímos excertos que tratam do desempenho dos surdos down na aquisição da língua de sinais, durante as sessões de terapias e fala (fonoaudiologia) que frequentam:

- Permanece apresentando evolução no processo de aquisição da linguagem;

- Havia dificuldade em compreender solicitações e regras simples de jogos;

- Compreende sentenças e solicitações simples;

- Há algumas "trocas" na configuração da mão ao sinalizar.

Esses excertos demonstram uma regularidade discursiva por parte de todos os profissionais que trabalham diretamente com os alunos surdos down, marcando a dificuldade destes sujeitos para adquirir e desenvolver a língua de sinais. A aquisição dessa língua é vista por esses profissionais como uma "capacidade" a ser desenvolvida pelos alunos e, para isso, são criadas estratégias que potencializam este aprendizado. Quando não desenvolvem a "capacidade" de se expressar em sinais, mas compreendem o que é sinalizado, aparecem situações como a descrita abaixo:

Quando eu me expresso em sinais ela entende, percebo que é mais fácil, mas ela se expressar em LS tem mais dificuldade. (Professora Laura, 2010)

A língua de sinais se apresenta como algo à parte nos relatórios de avaliação, separada das demais áreas do conhecimento. É como se fosse possível dissociar a LIBRAS do ensino de um modo geral. Apenas a língua portuguesa se apresenta interligada com a língua de sinais. Ao lado de cada área do 
conhecimento é inscrita a disciplina a que esta se refere, por exemplo: "conhecimento linguístico (língua de sinais e língua portuguesa); conhecimento lógico matemático (matemática e ciências); formação humana (ensino religioso); informática (conhecimento de informática); desenvolvimento psicomotor (educação física e educação artística); e estudos sociais (história e geografia)."

Nos documentos analisados, encontramos atividades propostas para os surdos down que têm como objetivo evitar ou contornar o risco eminente da não aprendizagem desses sujeitos ou o risco de não conseguirem se comunicar conforme o padrão linguístico da escola. Algumas das regras linguísticas se referem à configuração de mãos e ao uso de classificadores e constam em objetivos trimestrais, tais como: "compreender as configurações de mãos simples"; "ler imagem sem texto, expressão facial, corporal e [uso de] classificadores."

Nas entrevistas, algumas professoras comentam sobre os seus trabaIhos em sala de aula quanto ao uso da configuração de mão e de classificadores:

\begin{abstract}
Down entende comunicação, é diferente, tem uma comunicação própria, e eu respeito seus sinais. Consegue se expressar, ela [Alice] tenta usar os classificadores, mas tem dificuldade em entendê-los e isso é próprio dela, eu respeito. (Professora Laura, 2010)
\end{abstract}

O uso correto das regras linguísticas pode ser observado pelos alunos surdos down através dos sinais feitos pelo professor surdo e por professores ouvintes fluentes na língua de sinais, mas alguns podem ter "dificuldades em entendê-las" e embora alguns professores respeitem o uso da língua feito pelos alunos, na área da educação de surdos, na maior parte das vezes, há o entendimento de que as regras da língua de sinais precisam ser respeitadas pelos seus usuários, sejam estes surdos sem deficiência ou surdos com deficiência.

O propósito do ensino da L1 e L2 é que a comunicação dos surdos down se desenvolva de tal modo que se pareça com a comunicação dos demais surdos, usuários fluentes da língua de sinais, como mostra o objetivo: "estimular a fluência da Língua de Sinais"e, desta forma, os conteúdos trabalhados com os surdos down possam estar cada vez mais próximos dos conteúdos trabalhados com os demais alunos surdos:

Ela [Alice] precisa mais de auxílio e de estar atenta e ela aceita bem, tu diz vamos fazer de novo e ela faz e trabaIho... mais questões assim..., não frases, palavras soltas, ela não compreende a frase, não adianta insistir. Já dos outros eu cobro as frases. (Professora Júlia, 2010)

As atividades descritas nas entrevistas das professoras, denotam, muitas vezes, uma comparabilidade e hierarquização da fluência em língua de sinais entre os alunos surdos e os alunos surdos down: 
com os outros alunos eu não necessito deste recurso, posso apenas contar a história em Libras que eles compreendem, é um ensino leve... (Professora Mariana, 2010).

A comparabilidade linguística e a hierarquização da fluência na comunicação em língua de sinais também ocorre entre os surdos down. Alice é considerada a "mais fluente" entre os três alunos. Bárbara "é mais ou menos fluente", "hoje está tendo um rendimento muito maior" e Cláudio, além de não ser fluente, "é confuso", "ele tem uma língua própria, não tem LS em função da questão motora e tem uma questão cognitiva muito séria em função da síndrome".

Busca-se gerenciar o risco da não-aprendizagem da língua de sinais com a criação de estratégias de ensino diferenciadas para os surdos down; acredita-se que o risco da não aprendizagem das línguas (língua portuguesa e língua de sinais) na modalidade escrita possa ser contornado com o ensino da língua de sinais e da repetição constante da mesma; o risco da não-compreensão dos conteúdos, de um modo geral, pode ser revertido através do apoio pedagógico, com o uso de imagem, figura e sinal; o risco da comunicação ficar reduzida a poucos gestos, dos alunos não entenderem e de não serem entendidos, pode também ser revertido com a repetição dos sinais; o risco de permanecerem com pouca habilidade motora e com "defeito" na configuração de mãos pode ser contornado a partir da prática constante de exercícios artísticos que envolvam a motricidade fina.

Talvez o risco de deixarem a escola sem serem fluentes na língua de sinais, de atingirem apenas parcialmente a grande maioria dos objetivos propostos durante todo o período escolar, possa ser reduzido se houver uma mudança na visão de ensino para os alunos surdos down que não tenha tantas exigências conteudistas. Mas isto pode acarretar em outro risco: o risco dos familiares dos alunos surdos down se posicionarem contrários ao ensino voltado mais ao aprendizado de oficinas do que o aprendizado formal.

A normalização linguística pode ser vista operando em todos os fatores anteriormente descritos, pois o comum na escola de surdos, até há alguns anos, era atender alunos surdos sem deficiências, e era com estes que as professoras estavam acostumadas, preparadas e habilitadas para trabalhar em sala de aula. Por isso, busca-se, hoje, gerenciar o risco da não-aprendizagem por meio de estratégias de ensino diferenciadas com os surdos down nas turmas de surdos, o que, na prática, não tem sido uma tarefa simples.

\section{Considerações finais}

Até há poucos anos, o aluno surdo, para garantir acesso à escola de surdos, precisava ser apenas surdo. Caso fosse identificada alguma deficiência associada à surdez, era sugerido que a família do aluno procurasse outros 
espaços de ensino. Em número reduzido e conforme o grau e/ou tipo de deficiência, alguns surdos com deficiências eram matriculados nas escolas de surdos.

Com o passar dos anos, a partir da política de inclusão escolar, essa situação vai se modificando, e a escola de surdos começa a receber um número expressivo de alunos surdos com deficiências, entre estes os surdos down. Nesse contexto, a necessidade do ensino em Libras não está mais no centro dos debates e passa-se a discutir as possíveis formas e/ou estratégias de ensino dos alunos surdos com deficiências, surdos, que passam a ser considerados "alunos de inclusão" pela comunidade escolar.

Ser um profissional fluente em Língua de Sinais e ter a formação na área da educação de surdos não é mais suficiente para o ensino de surdos com deficiências. E o trabalho anteriormente desenvolvido com "surdos normais e surdos puros", é tensionado no momento em que são incluídos os surdos que não estão no centro da norma surda.

As análises apresentadas neste artigo indicam algumas estratégias utilizadas pela escola para normalizar todos os sujeitos que dela fazem parte. A comparabilidade entre educandos surdos sem deficiência, o "normal surdo"e surdos down pode levar a práticas educacionais excludentes, em que o padrão de normalidade está pautado na possibilidade de aprender quando se estabelece uma comunicação pela Libras e através dela se pode aprender os conteúdos escolares. Mas quando este processo não acontece ou é mais lento, alguns sujeitos passam a ser entendidos como desviantes do processo educacional.

Os materiais analisados mostraram uma regularidade discursiva entre os diferentes campos de saberes - médico, social, psicológico e pedagógico que fabricam os surdos down como sujeitos dóceis, mas também com "limitações" e "dificuldades na linguagem compreensiva e expressiva" da Língua de Sinais.

Encerramos observando que nossa intenção neste artigo é a de tentarmos entender as condições do presente para que uma pedagogia da diferença surda, que inclua todos os surdos, possa acontecer. Mas, como Skliar (2003), pensamos que essa pedagogia seja (im)provável, uma vez que a diferença não pode ser capturada e compreendida em suas diferentes manifestações. Nosso comprometimento é com a busca de possíveis explicações para a determinação das distintas posições que ocupam os sujeitos surdos nas escolas, mesmo quando essas escolas são específicas para esses sujeitos. Posições que são definidas a partir de um gradiente de (a)normalidade constituído na modernidade e que fabrica nossa relação com a diferença. 


\section{Referências}

BRASIL, MEC. Diretrizes para a Educação Especial na Educação Básica. 2001. [online]. Disponível em: <http://portal.mec.gov.br/cne/arquivos/pdf/ CEB0201.pdf>. Acesso em: 15 fev. 2010.

EWALD, F. Foucault, a Norma e o Direito. 2. ed. Lisboa: Vega, 1993.

FERREIRA, A. B. de H. Miniaurélio: o minidicionário da língua portuguesa. 6.ed. ver. Atualiz. Curitiba: Posigraf, 2004.

FONSECA, M. A. Michel Foucault e a construção do sujeito. São Paulo: EDUC, 1995.

Vigiar e Punir: história da violência nas prisões. Tradução de Raquel Ramalhete. 30.ed. Petrópolis: Editora Vozes, 2005.

Segurança, Território e População: curso dado no Collège de France (1977-1978). Trad. Eduardo Brandão. São Paulo: Martins Fontes, 2008.

FOUCAULT, M. Vigiar e punir: história da violência nas prisões. Tradução de Raquel Ramalhete. 30.ed. Petrópolis: Editora Vozes, 2005.

Segurança, Território e População: curso dado no Collège de France (1977-1978). Trad. Eduardo Brandão. São Paulo: Martins Fontes, 2008.

LUNARDI, M. L. A produção da anormalidade surda nos discursos da educação especial. Porto Alegre: UFRGS, 2003. 200 f. Tese (Doutorado em Educação) - Programa de Pós-Graducação em Educação, Faculdade de Educação, Universidade Federal do Rio Grande do Sul, Porto Alegre, 2003.

PORTOCARRERO, V. Instituição escolar e normalização em Foucault e Canguilhem: Dossiê Michel Foucault. Educação \& Realidade, Porto Alegre, v. 29, n. 1, jan./jun. 2004. Disponível em: <http://www.pgfil.uerj.br/pdf/publicacoes/ portocarrero/portocarrero_04.pdf>.Acesso em: 20 fev. 2010.

SKLIAR, C. Pedagogia (improvável) da diferença: e se o outro não estivesse aí? Rio de Janeiro: DP\&A, 2003.

\section{Correspondência}

Liège Gemelli Kuchenbecker - Rua Ernesto da Fontoura, 1480, apto. 305. Bairro São Geraldo. 90230-090. Porto Alegre, RS.

Email: liegegk@terra.com.br - asthoma@terra.com.br

Recebido em 05 de outubro de 2011

Aprovado em 03 de novembro de 2011 
